\title{
Dynamic Characteristics Analysis of High-rise Connected Structure
}

\author{
Ji Dongyu \\ Hunan Urban Construction College \\ Xiangtan, China \\ hnjdy@126.com
}

\author{
Song Chuncao \\ North China University of Water Resources and Electric \\ Power \\ Zhengzhou, China \\ 285893543@qq.com
}

\begin{abstract}
High-rise connected structure has been widely used in the country, at present research of its seismic behavior is less. In order to have a clear understanding for dynamic characteristics of high-rise connected structure, and improving the structure's seismic performance. This paper adopts the universal finite element calculating software to simulate and calculate high-rise connected structure, and gives natural frequency and vibration mode of high-rise connected structure, and analyses calculation results, research results can provides certain theoretical basis for seismic design of high-rise connected structure. The results showed that, high-rise connected structure is a more complex structure, vibration mode not only include transverse and longitudinal vibration mode, but also include reverse and space combination vibration mode. These show that high-rise connected structure's dynamic characteristics are more complicated.
\end{abstract}

Kewords-High-rise connected structure; Dynamic characteristics; Finite element method; Vibration mode; Frequency.

\section{INTRODUCTION}

High-rise connected structure has been widely used in the country, but at present home and abroad the seismic behavior of such structure system has not yet formed a unified understanding, in a high seismic intensity area design of such structure system lacks enough theoretical basis, test and practical experience. Because high-rise connected structure contains two kinds of complex structure system, enlarged base and twin-tower, at present research of its seismic behavior is less[1]. This paper adopts large finite element software ANSYS to establish the finite element model of high-rise connected structure, and gets natural frequency and vibration mode of high-rise connected structure, and analyses calculation results, research results can provides certain theoretical basis for seismic design of high-rise connected structure[2].

\section{SUMMARY}

High-rise connected structure is twin-tower building with enlarged base, its base is 3 floors, two towers all are 20 floors, story height is $4 \mathrm{~m}$, total height is $92 \mathrm{~m}$. This building is connected by connecting body on the 20th floor. Connecting body is reinforced concrete plate, foundation part adopts pile foundation.

\section{CAlCUlation Model}

\section{A Model Parameters.}

The concrete strength grade of high-rise connected structure is C40, elastic modulus of concrete is $32.5 \mathrm{GPa}$, poisson's ratio of concrete is 0.2 , density is $2500 \mathrm{~kg} / \mathrm{m} 3$, damping ratio is 0.05[3-4]. Elastic modulus of soft soil layer of foundation is $0.5 \mathrm{GPa}$, poisson's ratio is 0.35 , density is $1800 \mathrm{~kg} / \mathrm{m} 3$, damping ratio is 0.05 . Elastic modulus of bedrock layer of foundation is $50 \mathrm{GPa}$, poisson's ratio is 0.25 , density is $2600 \mathrm{~kg} / \mathrm{m} 3$, damping ratio is $0.05[5]$.

\section{$B \quad$ Finite element model.}

In the finite element calculation model of twin-tower building with enlarged base, beams and columns adopt Beam188 element, floor and seismic shear walls adopt Shell63 element, foundation soil adopt Solid45 element[6-7].

Length of foundation is $508 \mathrm{~m}$, width of foundation is $280 \mathrm{~m}$, depth of foundation is $136 \mathrm{~m}$ [8-9]; foundation includes soft soil layer and bedrock layer, depth of soft soil layer is $16 \mathrm{~m}$, depth of bedrock layer is $120 \mathrm{~m}$. In the finite element calculation model of high-rise connected structure, $\mathrm{Y}$ direction is height direction, $\mathrm{Z}$ direction and $\mathrm{X}$ direction is horizontal direction[10], which shows in the Fig .1. 


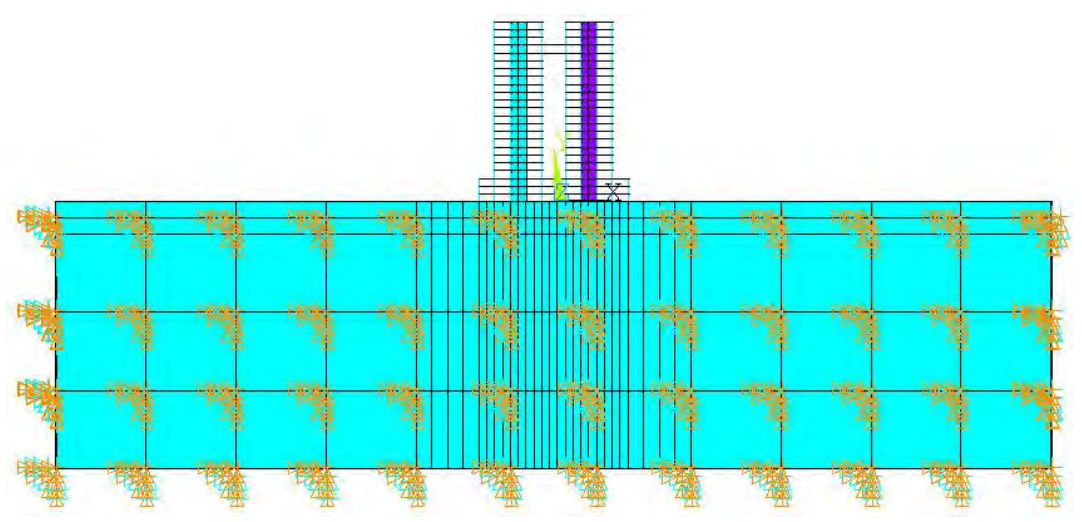

Figure 1. Calculation model of high-rise connected structure

\section{ANALYSIS OF CALCULATION RESULTS}

This paper calculates and analyses dynamic characteristics of high-rise connected structure, obtain the first ten vibration modes and frequencies of this structure.
Each order vibration mode of high-rise connected structure shows in the Fig .2 to Fig .11.

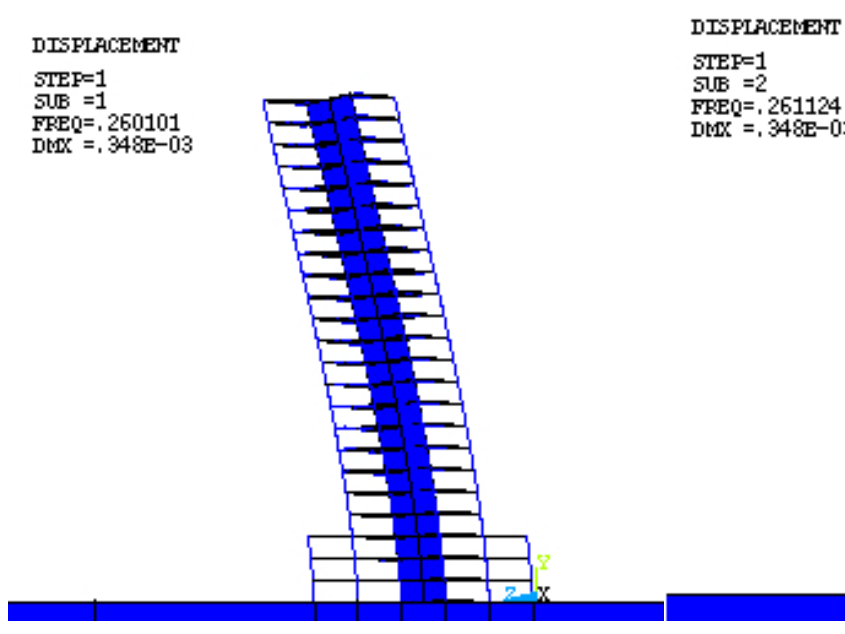

Figure 2. The first order vibration mode

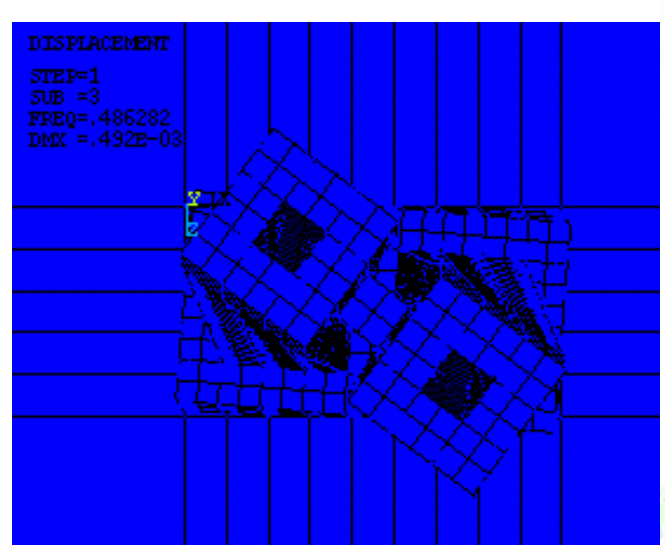

Figure 4. The third order vibration mode

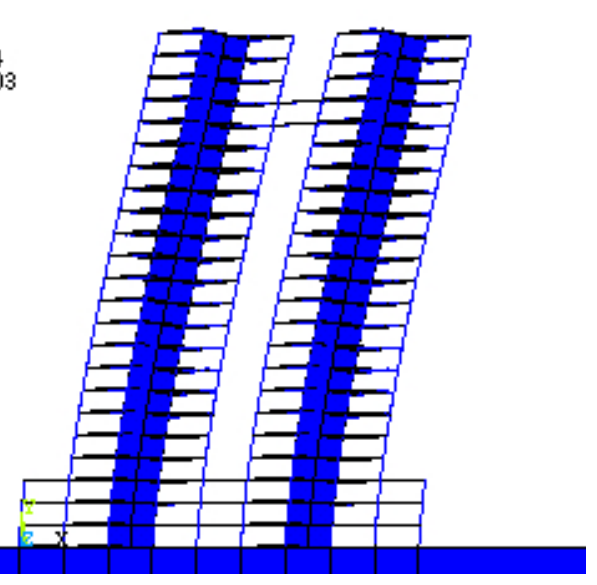

Figure 3. The second order vibration mode

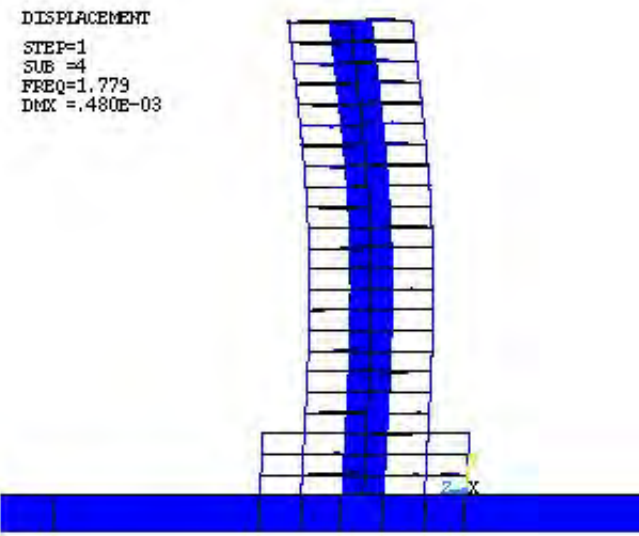

Figure 5. The fourth order vibration mode 


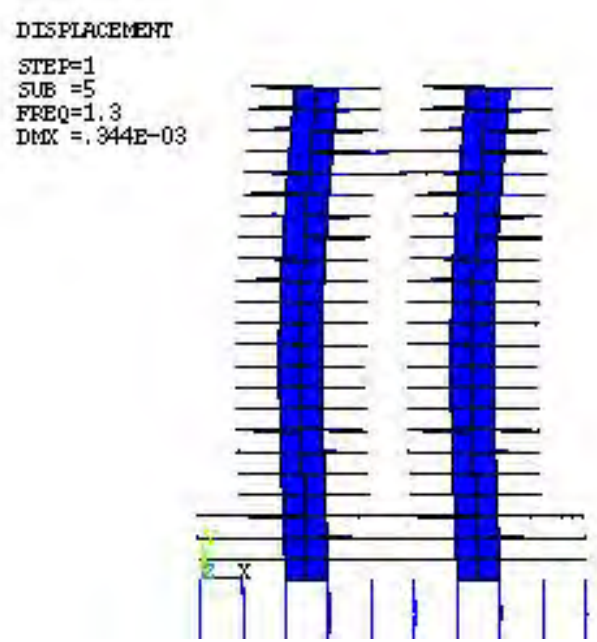

Figure 6 . The fifth order vibration mode

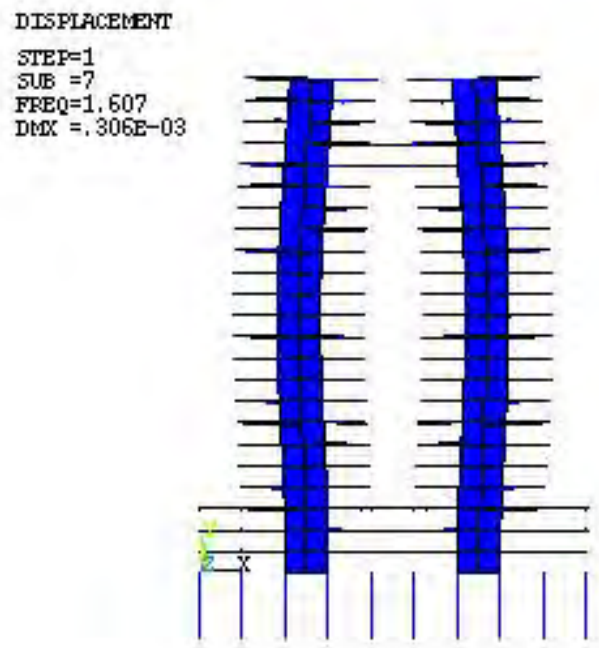

Figure 8 . The seventh order vibration mode

DISPLACELERT

STEP $=1$

$\mathrm{SUB}=9$

$\mathrm{DtWX}=.518 \mathrm{E}-03$

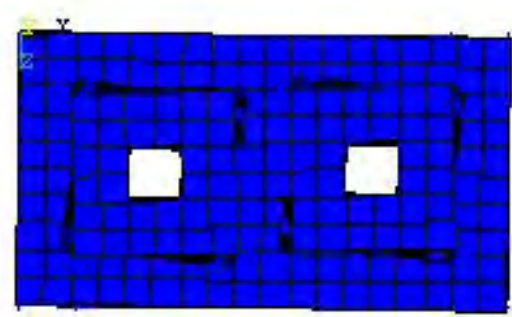

Figure 10. The ninth order vibration mode
DISPLACELENT

STEF $=1$

SUB $=6$
FRE $0=1,36$

$\mathrm{DWX}=, 427 \mathrm{E}-03$

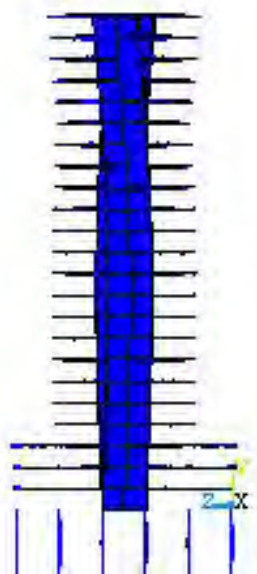

Figure 7 . The sixth order vibration mode

\section{DISPLACELENI \\ STEP $=1$ \\ $\mathrm{SUB}=8$ \\ FRE $0=1.65$}

DLX $=.433 \mathrm{E}-03$

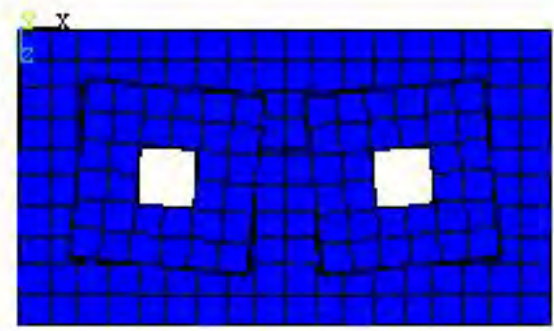

Figure 9. The eighth order vibration mode

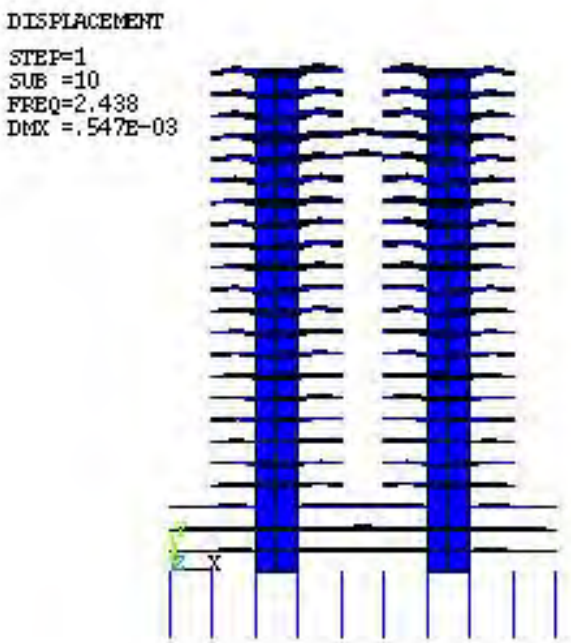

Figure 11. The tenth order vibration mode 
As can be seen from the Fig .2 to the Fig .11, the difference value of the first three vibration modes and frequencies of high-rise connected structure is very small, the first and the second order vibration mode of high-rise connected structure are translational vibration mode, the third order vibration mode is torsional vibration mode, the fourth order vibration mode is two order translational vibration mode, the fifth order vibration mode is local vibration mode, the sixth order vibration mode is two order translational and local vibration mode, the seventh order, eighth order, ninth order, tenth order vibration mode is torsional vibration mode. The first and the second order vibration mode of high-rise connected structure are all translational vibration mode, the vibration mode of upper structure is the main vibration mode, shows that integral stiffness of lower structure is bigger.

\section{CONCLUSION}

In conclusion, through the dynamic characteristic analysis of high-rise connected structure, we can obtain the following conclusion. High-rise connected structure is a more complex transmission tower, its vibration mode includes not only translational vibration mode, longitudinal vibration mode, local vibration mode, but also torsional vibration mode and composite space vibration mode, shows that the dynamic characteristics of high-rise connected structure is more complex. The first and the second order vibration mode of high-rise connected structure are given priority to translational vibration mode, shows that the vibration mode of high-rise connected structure is given priority to translational vibration mode in the process of normal operation.

\section{REFERENCE}

[1] Chaowei Xi, Yiping Jiang, Daolin Tong, Jiguang Li. Shanking table model test of a twin-tower connecting tall building with enlarged base and transfer storey[J]. Journal of Building Structures, 2009(5): 102-107.

[2] Jianzhuang Xiao,Changqing Wang,Jie Li et al. Shake-Table Model Tests on Recycled Aggregate Concrete Frame Structure [J]. AC structural journal,2012,109(6):777-786.

[3] Xingfu Hu, Feng Xiong, Hui Li. The effect for seismic behavior of the high-rise buildings with twin towers and large chassis by the shear wall's thickness [J]. Sichuan Building Science, 2005(4): 88-90.

[4] G. A. Lesieutre,J. A. Browne,M. I. Frecker et al. Scaling of Performance, Weight, and Actuation of a 2-D Compliant Cellular Frame Structure for a Morphing Wing [J]. Journal of intelligent material systems and structures,2011,22(10):979-986.

[5] Thang Nguyen Dao,John W. van de Lindt. Loss Analysis for Wood Frame Buildings during Hurricanes. I: Structure and Hazard Modeling $[\mathrm{J}]$. Journal of Performance of Constructed Facilities,2012,26(6):729-738

[6] Xucheng Wang. Finite Element Method [M]. Tsinghua University Press, 2003.

[7] Alessandra Fiore,Adriana Netti,Pietro Monaco et al. The influence of masonry infill on the seismic behaviour of RC frame buildings [J]. Engineering structures,2012,44(Nov.):133-145.

[8] Bofang Zhu. Finite Element Method Principle and Application [M]. China Water Conservancy and Hydropower Press, 1998

[9] Christoph Adam, Clemens Jager. Simplified collapse capacity assessment of earthquake excited regular frame structures vulnerable to P-delta [J]. Engineering structures, 2012, 44(Nov.): 159-173.

[10] Lincy Pyl,Luc Schueremans,Willem Dierckx et al. Fire safety analysis of a 3D frame structure based on a full-scale fire test [J]. Thin-Walled structures,2012,61:204-212. 